\title{
Implementation of RFID for Verification of PC Usage in the UMSIDA's Electrical Engineering Laboratory Based on the Internet of Things
}

\section{Implementasi RFID untuk Verifikasi Penggunaan PC di Laboratorium Teknik Elektro Umsida Berbasis Internet Of Things}

\author{
Muhammad Drajad Kuncoro Aji ${ }^{1}$, Jamaaluddin Jamaaluddin ${ }^{2}$, Izza Anshory ${ }^{3}$, Akhmad Ahfas ${ }^{4}$ \\ \{171020100089@umsida.ac.id ${ }^{1}$, jamaaluddin@umsida.ac.id ${ }^{2}$, izzaanshory@umsida.ac.id ${ }^{3}$, ahfas@umsida.ac.id $\left.{ }^{4}\right\}$ \\ Program Studi Teknik Elektro, Fakultas Sains dan Teknologi, Universitas Muhammadiyah Sidoarjo
}

\begin{abstract}
Every day visitors to the UMSIDA electrical engineering laboratory have different goals. The main function of the laboratory is as a practicum for electrical engineering students and is also used to work on coursework. This study aims to control the use of laboratory PCs using Internet of Things-based RFID card verification. The application of RFID connected to the Wemos DI Mini is expected to be able to reduce unexpected actions such as theft and hacking of data on the PC. The PC will be installed with an RFID reader to verify the RFID card as the initial stage of $P C$ use. The results of the research trials showed that by bringing the RFID card from $0 \mathrm{~cm}$ to $2.5 \mathrm{~cm}$ closer to the RFID reader, the RFID card was successfully verified effectively. When the RFID card is successfully verified by the $R F I D$ reader, the $P C$ will automatically turn on, the verification results will be displayed on the $16 x 2 L C D$ and android smartphone so that they can monitor every time and get an android notification that sends information that the verification process was successful and the PC is on. Laboratory PCs are safer from unwanted use by using RFID technology that is connected to the Wemos D1 Mini for monitoring and controlling via a smartphone remotely in realtime because before using a PC, it must go through a verification process.
\end{abstract}

Keywords - RFID; PC (Personal Computer); Wemos DI Mini

\begin{abstract}
Abstrak. Setiap hari pengunjung laboratorium teknik elektro UMSIDA memiliki tujuan yang berbeda-beda. Fungsi utama dari laboratorium adalah sebagai praktikum untuk mahasiswa teknik elektro dan juga digunakan untuk mengerjakan tugas kuliah. Penelitian ini bertujuan untuk mengontrol penggunaan PC laboratorium menggunakan verifikasi kartu RFID berbasis Internet of Things. Penerapan RFID yang dihubungkan ke Wemos D1 Mini diharapkan mampu mengurangi tindakan yang tidak diharapkan seperti pencurian dan peretasan data yang ada di dalam PC. PC akan dipasang RFID reader guna memverifikasi Kartu RFID sebagai tahap awal penggunaan PC. Hasil uji coba penelitian menunjukkan bahwa dengan mendekatkan kartu RFID dari $0 \mathrm{~cm}$ hingga 2,5 cm ke RFID reader maka kartu RFID berhasil diverifikasi dengan efektif. Ketika kartu RFID berhasil diverifikasi oleh RFID reader maka PC akan otomatis menyala, hasil verifikasi akan ditampilkan di LCD $16 \times 2$ dan smartphone android agar dapat memonitoring setiap waktu serta mendapatkan notifikasi android yang mengirimkan informasi bahwa proses verifikasi berhasil dan PC telah menyala. PC laboratorium lebih aman dari penggunaan yang tidak diinginkan dengan menggunakan teknologi RFID yang dihubungkan ke Wemos D1 Mini untuk memonitoring dan mengontrol melalui smarthphone dari jarak jauh secara realtime, karena sebelum penggunaan PC harus melalui proses verifikasi.
\end{abstract}

Kata Kunci-RFID; PC (Personal Computer); Wemos D1 Mini

\section{Pendahuluan}

Salah satu kebutuhan pokok manusia pada zaman modern sekarang ini adalah energi listrik dan indikator kemajuan suatu bangsa salah satunya ditentukan oleh kebutuhan energi listrik. Saat ini masyarakat masih menggunakan fosil untuk memenuhi kebutuhan energinya. Jadi, semakin lama semakin berkurang, pertumbuhan rata-rata kebutuhan energi diperkirakan mencapai 4,7\% per tahun selama tahun 2011 hingga tahun 2030[1]. Peningkatan jumlah pemakaian kendaraan berbahan bakar fosil yang berlebihan di kota-kota besar yang membengkak tiada henti, karena masyarakat secara tidak masuk akal membeli skuter, sepeda motor dan mobil sehingga menyebabkan pencemaran udara[9]. Pengoperasian sistem kelistrikan ini dimulai dari sistem pembangkit, sistem transmisi, dan sistem distribusi ke pelanggan[2]. Kebutuhan akan energi listrik sebanding dengan berkembangnya teknologi saat ini. Perkembangan teknologi yang pesat membuat manusia berlomba-lomba untuk mengembangkan peralatan yang dapat mempermudah pekerjaan manusia[3]. Beberapa masalah yang terjadi saat ini di beberapa negara di dunia adalah meningkatnya jumlah emisi $\mathrm{CO}_{2}$, berkurangnya ketersediaan sumber daya alam yang tidak terbarukan, terbatasnya ketersediaan lokasi parkir, dan polusi udara[10].

Teknologi memegang peranan yang sangat penting dalam kehidupan manusia[11]. Kemajuan teknologi yang pesat memberikan banyak kemudahan dalam dunia industri[12]. Indonesia memiliki kebutuhan energi untuk menggerakkan perekonomian di sektor industri yang diperkirakan tetap dominan dari tahun 2016 hingga 2050[13]. Salah satu perkembangan teknologi yakni verifikasi pada penggunaan PC menggunakan RFID berbasis Internet of Things. 
Pengertian verifikasi menurut Kamus Besar Bahasa Indonesia (KBBI) adalah pemeriksaan tentang kebenaran laporan, pernyataan, perhitungan uang, dan sebagainya. Sistem verifikasi bertujuan unuk memastikan dan membuktikan bahwa sesuatu benar atau ada. Kecanggihan teknologi pada zaman modern ini membawa dampak positif dan negatif bagi manusia. Dampak positif dari kecanggihan teknologi ialah suatu pekerjaan manusia dapat dipermudah dengan bantuan teknologi seperti robot atau Artificial Intelligence (AI). Namun, kecanggihan teknologi juga membawa dampak negatif bagi manusia salah satunya perihal keamanan. Suatu sistem dapat dengan mudahnya diretas jika tidak memiliki pengaman ganda. Oleh karena itu, peneliti menyadari bahwa menambahkan tingkat keamanan pada komputer merupakan hal yang perlu dilakukan. Sebagai inovasi menambahkan keamanan serta memudahkan menghidupkan komputer, maka dirancanglah sebuat alat Implementasi RFID Untuk Verifikasi Penggunaan PC di Laboratorium Teknik Elektro UMSIDA Berbasis Intenet of Things. Sistem keseluruhan dari alat yang akan dibuat adalah ketika mahasiswa akan menggunakan Personal Computer (PC) di laboratorium teknik elektro, maka mahasiswa harus terlebih dahulu mendekatkan kartu RFID ke RFID reader untuk proses verifikasi. Apabila kartu RFID yang terbaca oleh RFID reader sesuai maka PC akan otomatis hidup dan mahasiswa memiliki hak akses untuk mengoperasikan PC. Namun, mahasiswa tidak akan diberikan hak akses untuk mengoperasikan PC dan PC tidak dapat hidup jika kartu RFID yang terbaca oleh RFID reader tidak sesuai. Data hasil verifikasi akan ditampilkan dan dikontrol melalui smartphone secara wireless dengan jaringan internet. Dengan inovasi alat tersebut diharapkan mampu menambah keamanan ekstra pada PC dan mampu mengurangi hingga menghilangkan tindakan yang tidak diinginkan seperti menggunakan PC tanpa izin, peretasan data dan pencurian PC.

Radio Frequency Identification atau disingkat menjadi RFID merupakan suatu teknologi yang menyatukan fungsi kopling elektromagnetik atau elektrostatis dengan pori-pori frekuensi radio pada spektrum elektromagnetik untuk mengidentifikasi suatu objek. Teknologi RFID dinilai sangat tepat diperuntukkan sebagai sistem otomatis dan mudah digunakan. Teknologi RFID juga menggabungkan kelebihan yang tidak dapat diberikan oleh teknologi identifikasi lainnya. RFID dapat disediakan pada peralatan yang hanya dapat dibaca (read only) ataupun dapat dibaca dan ditulis (read / write), tidak membutuhkan kontak langsung ataupun jalur cahaya untuk tetap dapat bekerja, dapat beroperasi dalam segala kondisi keadaan, serta memberikan tingkat integritas yang tinggi terhadap datanya. Sebagian besar sistem identifikasi yang menggunakan RFID pada umumnya, tag ataupun transporter didekatkan ke sebuah objek. Pada saat tag melewati bidang yang dihasilkan oleh RFID reader yang sesuai dengan tag, tag tersebut akan mengirimkan informasi dari tag ke RFID reader, maka objek dapat diidentifikasi. Pada tiap tag memiliki informasi yang beragam dan berbeda dengan tag lainnya seperti nomor seri, model, warna, lokasi, perancangan, dan data lainnya dari objek yang diidentifikasi. Penggunaan RFID biasanya digunakan sebagai otomasi, identifikasi, dan autentikasi[4].

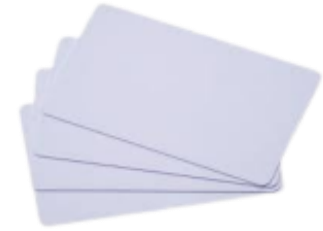

Gambar 1. Kartu RFID MFRC522[5]

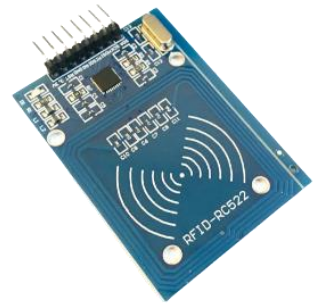

Gambar 2. RFID Reader MFRC522

Wemos D1 Mini merupakan suatu papan elektronika yang di dalamnya telah mempunyai firmware dan perangkat keras dengan fungsi wifi. Menggunakan chip ESP8266 (ESP-12S), memiliki flash memory 4M Bytes, memiliki pin input / output yang berjumlah 12 pin yang terdiri dari 11 pin input / output digital dan 1 pin analog input (maksimal input 3.2V), dan memiliki koneksi USB, colokan listrik serta tombol untuk mereset. Pin-pin ini berisi tentang semua hal yang dibutuhkan untuk menunjang kebutuhan mikrokontroler. Desain Wemos D1 Mini memungkinkan peneliti untuk dengan mudah memetakan peletakan pin dan mengetahui berbagai aspek mikrokontroler Wemos D1 Mini[6].

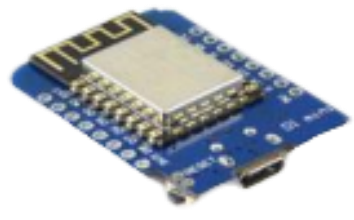

Gambar 3. Wemos D1 Mini[7]

Liquid Crystal Display (LCD) merupakan komponen elektronika yang dapat memberikan informasi berupa tampilan teks dan terbuat dari bahan kristal yang bekerja dengan sistem dot matrix. Pada penelitian ini LCD 16 x 2 yang digunakan dapat menampilkan teks hingga 32 karakter, termasuk 2 baris, setiap baris dapat menampilkan teks hingga 16 karakter. 
Modul I2C atau singkatan dari Inter Integrated Circuit merupakan modul interface antara LCD 16 x 2 dengan mikrokontroler Wemos D1 Mini. Modul I2C digunakan untuk meminimalisir pemakaian pin pada LCD 16 x 2. Modul ini mempunyai 4 pin yang dihubungkan ke Wemos D1 Mini. Wemos D1 Mini telah mendukung komunikasi I2C dengan modul LCD I2C, hanya menggunakan 2 pin Wemos D1 Mini untuk mengontrol LCD 16 x 2 yakni pin D1 (SCL) dan pin D2 (SDA) serta vcc dan ground sebagai sumber tegangan untuk menyalakan LCD I2C[8].

\section{METODE}

\section{A. Blok diagram sistem}

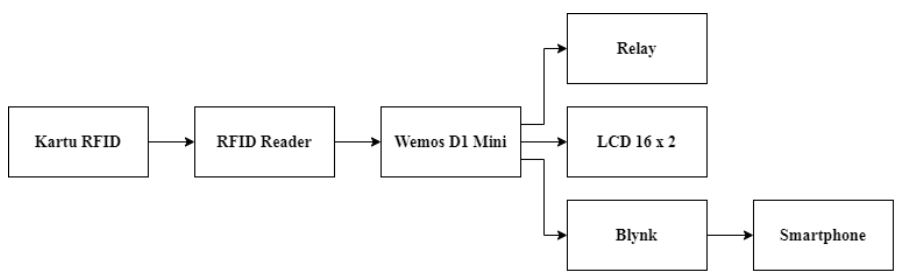

Gambar 4. Blok Diagram Sistem

Dapat dilihat berdasarkan gambar 4 blok diagram sistem sekarang yakni pada bagian input menggunakan sensor RFID untuk memperoleh data berupa nomor UID dari kartu RFID yang dibaca oleh RFID reader, data tersebut selanjutnya akan diolah pada bagian proses menggunakan mikrokontroler Wemos D1 Mini. Pada pengolahan data terdapat dua jenis data yang diolah yaitu, yang pertama jika kartu RFID yang ditempelkan atau dibaca oleh RFID reader sama dan cocok maka Wemos D1 akan memberi perintah berupa logika "High" pada relay sehingga PC akan menyala dan LCD 16 × 2 menampilkan informasi berupa teks "PROSES VERIFIKASI BERHASIL, PC TELAH MENYALA", serta LCD pada aplikasi Blynk juga akan menampilkan bahwa PC telah hidup. Sedangkan jika kartu RFID yang terbaca tidak sama dan tidak cocok maka PC tidak akan bisa menyala, LCD bertuliskan "PROSES VERIFIKASI GAGAL, KARTU TIDAK SESUAI.” dan smartphone akan mendapatkan notifikasi untuk segera mengecek smartphone, Untuk dapat menampilkan informasi hasil verifikasi ke smarpthone maka alat pada hardware harus terlebih dahulu terhubung dengan jaringan internet, jika telah terhubung dengan jaringan internet maka dapat menerima notifikasi serta dapat menampilkan hasil verifikasi.

\section{B. Flowchart sistem}

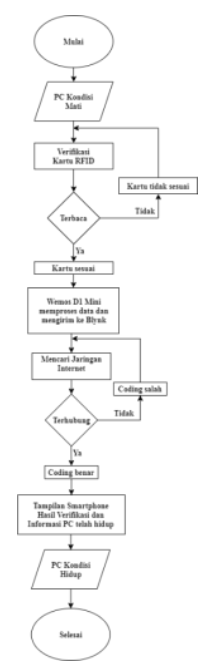

Gambar 5. Flowchart Sistem

Penjelasan flowchart sistem sebagai berikut :

1. Mulai : Tahapan awal dari proses Implementasi RFID Untuk Verifikasi Penggunaan PC di Laboratorium Teknik Elektro UMSIDA Berbasis Internet Of Things dengan menghubungkan alat pada sumber tegangan dan menekan tombol ON agar alat mendapat suplai tegangan.

2. PC Kondisi Mati : Setelah alat dalam kondisi on, namun kondisi awal PC (Personal Computer) tetap mati.

3. Scan Kartu RFID : Mendekatkan kartu RFID ke RFID reader untuk proses scaning kartu RFID sebagai tahap verifikasi penggunaan PC.

4. Terbaca : Pada saat proses scaning kartu RFID berhasil terbaca oleh RFID reader maka data tersebut akan diolah mikrokontroler Wemos D1 Mini, jika tidak terbaca maka proses mengulang kembali proses scaning.

5. Wemos D1 Mini : Data hasil proses scaning kartu RFID yang berhasil terbaca akan diolah pada Wemos D1 mini dan akan ditampilkan ke LCD 16 × 2 dan smartphone. 
6. Mencari Jaringan Internet : Agar hasil verifikasi berhasil dilakukan dan dapat ditampilkan pada smartphone maka alat harus terlebih dahulu terhubung dengan jaringan internet atau wifi.

7. Terhubung : Jika mikrokontroler Wemos D1 Mini sudah terhubung dengan internet maka alat dapat menampilkan informasi hasil verifikasi scaning kartu RFID dan notifikasi Blynk.

8. Smartphone Android : Informasi hasil verfikasi scaning kartu RFID dan informasi PC telah hidup akan ditampilkan pada smarphone melalui aplikasi Blynk.

9. PC Kondisi Hidup : Kondisi akhir PC akan hidup ketika berhasil melalui proses scaning kartu RFID.

10. Selesai : Tahapan akhir dari proses Implementasi RFID Untuk Verifikasi Penggunaan PC di Laboratorium Teknik Elektro UMSIDA Berbasis Internet Of Things ketika semua sistem telah berjalan dengan baik dan benar sesuai flowchart sistem yang telat dibuat.

\section{Rangkaian sistem keseluruhan}

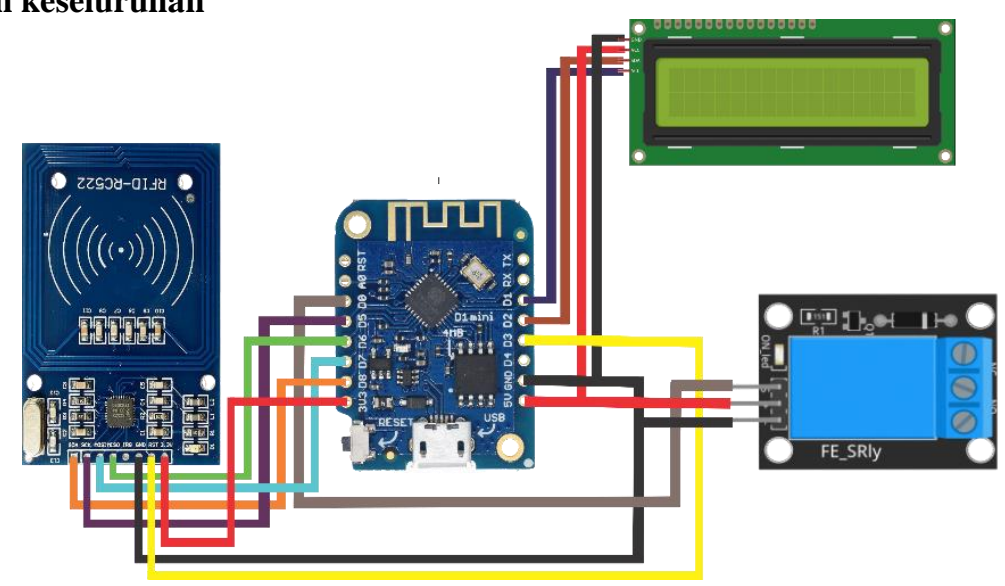

Gambar 6. Rangkaian Sistem Keseluruhan

Berikut tabel pengalamatan pin seluruh komponen yang terhubung pada Wemos D1 Mini :

Tabel 1. Pengalamatan Pin Pada Rangkaian Sistem Keseluruhan

\begin{tabular}{|c|c|c|c|}
\hline No & Nama Komponen & Alamat Pin pada Hardware & Alamat Pin pada Wemos D1 Mini \\
\hline 1 & \multirow{8}{*}{ RFID MCFR522 } & SDA & D8 \\
\hline 2 & & SCK & D5 \\
\hline 3 & & MOSI & D7 \\
\hline 4 & & MISO & D6 \\
\hline 5 & & IRQ & - \\
\hline 6 & & GND & GND \\
\hline 7 & & RST & D3 \\
\hline 8 & & $3.3 \mathrm{~V}$ & $3,3 \mathrm{~V}$ \\
\hline 9 & \multirow{4}{*}{$\mathrm{LCD} 16 \times 2+\mathrm{I} 2 \mathrm{C}$} & SDA & D2 \\
\hline 10 & & SCL & D1 \\
\hline 11 & & VCC & $5 \mathrm{~V}$ \\
\hline 12 & & GND & GND \\
\hline 13 & \multirow{3}{*}{ Relay 1 channel } & Data & D0 \\
\hline 14 & & VCC & $5 \mathrm{~V}$ \\
\hline 15 & & GND & GND \\
\hline
\end{tabular}

\section{Hasil dan Pembahasan}

\section{A. Desain mekanik alat}
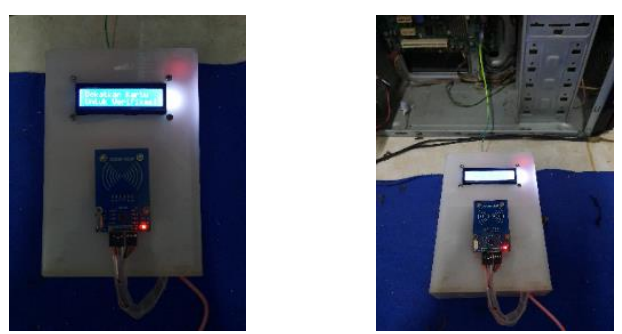

Gambar 7. Desain Mekanik alat Keseluruhan 
Ukuran tempat untuk mengisi seluruh komponen yang digunakan pada alat implemetasi RFID untuk verifikasi menggunakan box akrilik warna putih dengan volume $12,5 \mathrm{~cm}$ x 17,5 cm x 5,5 cm. Di dalam box tersebut diisi dengan sensor RFID, Wemos D1 Mini, LCD 16 x 2 I2C, dan relay 1 channel. Setelah merakit seluruh komponen lalu selanjutnya melakukan tahap pengujian keseluruhan dan pengambilan data guna mengetahui alat yang dibuat sudah bekerja sesuai dengan yang direncanakan atau belum.

\section{B. Pengujian sensor rfid mfre522}

Pengujian sensor RFID MFRC522 dilakukan untuk mengetahui sensor RFID dapat memverifikasi kartu RFID dengan baik dan benar. Berikut langkah-langkah pengujian sensor RFID MFRC522 :

1. Hubungkan pin 3.3V, RST, GND, MISO, MOSI SCK, SDA pada sensor RFID ke pin 3.3V, D8, GND, D6, D7, D5, D8 pada Wemos D1 Mini.

2. Hubungkan Wemos D1 Mini pada laptop / PC menggunakan kabel USB untuk menghidupkan alat.

3. Upload sketch program untuk memverifikasi kartu RFID.

4. Dekatkan kartu RFID ke RFID reader untuk proses verifikasi.

5. Uji sensor sebanyak 5 kali percobaan.
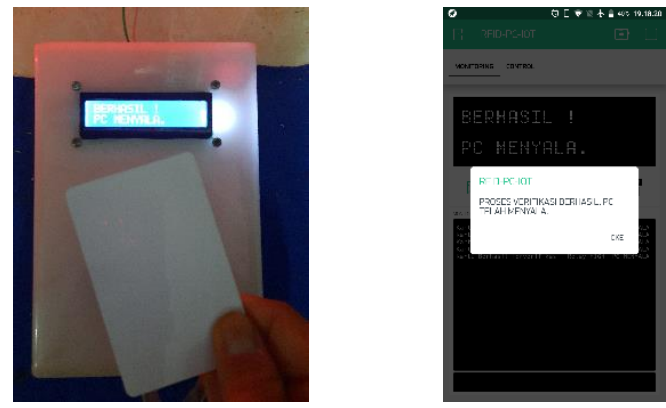

Gambar 8. Pengujian Sensor RFID MFRC522

Daril hasil pengujian sensor RFID MFRC522 tersebut didapatkan suatu data yang dicatat dalam bentuk tabel agar data tersebut dapat lebih mudah dihitung dan dianalisa.

Tabel 2. Tabel Pengujian Sensor MFRC522 dengan jarak $1 \mathrm{~cm}$ antara kartu RFID ke RFID reader

Tabel Pengujian Sensor MFRC522 dengan jarak $1 \mathrm{~cm}$ antara kartu RFID ke RFID reader.

\begin{tabular}{cccccccc}
\hline No & Percoban & $\begin{array}{c}\text { Kartu } \\
\text { RFID }\end{array}$ & Relay & $\begin{array}{c}\text { PC } \\
\text { (Personal } \\
\text { Computer }\end{array}$ & $\begin{array}{c}\text { Rata- } \\
\text { rata }\end{array}$ & $\begin{array}{c}\text { Standar } \\
\text { Deviasi }\end{array}$ & Keterangan Alat \\
\hline 1 & 1 & 1 & 1 & 1 & 1 & 0 & $\begin{array}{c}\text { PC menyala dan } \\
\text { notifikasi blynk } \\
\text { terkirim. }\end{array}$ \\
\hline 2 & 2 & 1 & 1 & 1 & 1 & 0 & $\begin{array}{c}\text { PC menyala dan } \\
\text { notifikasi blynk } \\
\text { terkirim. }\end{array}$ \\
\hline 3 & 3 & 1 & 1 & 1 & 1 & 0 & $\begin{array}{c}\text { PC menyala dan } \\
\text { notifikasi blynk } \\
\text { terkirim. }\end{array}$ \\
\hline 5 & 4 & 1 & 1 & 1 & 1 & 0 & $\begin{array}{c}\text { PC menyala dan } \\
\text { notifikasi blynk } \\
\text { terkirim. }\end{array}$ \\
\hline & 5 & 1 & 1 & 1 & 1 & 0 & $\begin{array}{c}\text { PC menyala dan } \\
\text { notifikasi blynk } \\
\text { terkirim. }\end{array}$ \\
\hline
\end{tabular}

Tabel 2 berisi data hasil pengujian sensor RFID MFRC522 diberi jarak $1 \mathrm{~cm}$ antara kartu RFID ke RFID reader. Terdapat 3 parameter jenis pengujian yaitu kartu RFID, relay dan PC (Personal Computer). Data hasil pengujian sensor RFID MFRC522 pada tabel 2 menjelaskan bahwa RFID reader yang diberi jarak $1 \mathrm{~cm}$ antara kartu RFID ke RFID reader dapat melakukan verifikasi kartu RFID dengan efektif, jika kartu RFID terverifikasi dengan benar maka sistem akan memberi logika "HIGH" pada relay yang terhubung dengan PC sehingga PC dapat menyala dan dapat mengirimkan notifikasi pada smartphone android melalui aplikasi blynk.

Tabel 3. Tabel Pengujian Sensor MFRC522 dengan jarak $2 \mathrm{~cm}$ antara kartu RFID ke RFID reader 
Procedia of Engineering and Life Science Vol. 1. No. 2 Juni 2021

Seminar Nasional \& Call Paper Fakultas Sains dan Teknologi (SENASAINS 2nd)

Universitas Muhammadiyah Sidoarjo

Tabel Pengujian Sensor MFRC522 dengan jarak 2 cm antara kartu RFID ke RFID reader.

\begin{tabular}{|c|c|c|c|c|c|c|c|}
\hline No & Percobaan & $\begin{array}{l}\text { Kartu } \\
\text { RFID }\end{array}$ & Relay & $\begin{array}{c}\text { PC } \\
\text { (Personal } \\
\text { Computer) } \\
\end{array}$ & $\begin{array}{l}\text { Rata- } \\
\text { rata }\end{array}$ & $\begin{array}{l}\text { Standar } \\
\text { Deviasi }\end{array}$ & Keterangan Alat \\
\hline 1 & 1 & 1 & 1 & 1 & 1 & 0 & $\begin{array}{c}\text { PC menyala dan } \\
\text { notifikasi blynk } \\
\text { terkirim. }\end{array}$ \\
\hline 2 & 2 & 1 & 1 & 1 & 1 & 0 & $\begin{array}{c}\text { PC menyala dan } \\
\text { notifikasi blynk } \\
\text { terkirim. }\end{array}$ \\
\hline 3 & 3 & 1 & 1 & 1 & 1 & 0 & $\begin{array}{c}\text { PC menyala dan } \\
\text { notifikasi blynk } \\
\text { terkirim. }\end{array}$ \\
\hline 4 & 4 & 1 & 1 & 1 & 1 & 0 & $\begin{array}{c}\text { PC menyala dan } \\
\text { notifikasi blynk } \\
\text { terkirim. }\end{array}$ \\
\hline 5 & 5 & 1 & 1 & 1 & 1 & 0 & $\begin{array}{c}\text { PC menyala dan } \\
\text { notifikasi blynk } \\
\text { terkirim. }\end{array}$ \\
\hline
\end{tabular}

Tabel 3 berisi data hasil pengujian sensor RFID MFRC522 diberi jarak $2 \mathrm{~cm}$ antara kartu RFID ke RFID reader. Terdapat 3 parameter jenis pengujian yaitu kartu RFID, relay dan PC (Personal Computer). Data hasil pengujian sensor RFID MFRC522 pada tabel 3 menjelaskan bahwa RFID reader yang diberi jarak $2 \mathrm{~cm}$ antara kartu RFID ke RFID reader dapat melakukan verifikasi kartu RFID dengan efektif, jika kartu RFID terverifikasi dengan benar maka sistem akan memberi logika "HIGH" pada relay yang terhubung dengan PC sehingga PC dapat menyala dan dapat mengirimkan notifikasi pada smartphone android melalui aplikasi blynk.

Tabel 4. Tabel Pengujian Sensor MFRC522 dengan jarak $3 \mathrm{~cm}$ antara kartu RFID ke RFID reader

Tabel Pengujian Sensor MFRC522 dengan jarak 3 cm antara kartu RFID ke RFID reader.

\begin{tabular}{|c|c|c|c|c|c|c|c|}
\hline No & Percobaan & $\begin{array}{l}\text { Kartu } \\
\text { RFID }\end{array}$ & Relay & $\begin{array}{c}\text { PC } \\
\text { (Personal } \\
\text { Computer) }\end{array}$ & $\begin{array}{l}\text { Rata- } \\
\text { rata }\end{array}$ & $\begin{array}{l}\text { Standar } \\
\text { Deviasi }\end{array}$ & Keterangan Alat \\
\hline 1 & 1 & 0 & 0 & $\mathrm{~T}=\mathrm{s}$ & 0 & 0 & $\begin{array}{c}\text { PC tidak menyala } \\
\text { karena kartu melebihi } \\
\text { jarak verifikasi. }\end{array}$ \\
\hline 2 & 2 & 0 & 0 & 0 & 0 & 0 & $\begin{array}{l}\text { PC tidak menyala } \\
\text { karena kartu melebihi } \\
\text { jarak verifikasi. }\end{array}$ \\
\hline 3 & 3 & 0 & 0 & 0 & 0 & 0 & $\begin{array}{l}\text { PC tidak menyala } \\
\text { karena kartu melebihi } \\
\text { jarak verifikasi. }\end{array}$ \\
\hline 4 & 4 & 0 & 0 & 0 & 0 & 0 & $\begin{array}{l}\text { PC tidak menyala } \\
\text { karena kartu melebihi } \\
\text { jarak verifikasi. }\end{array}$ \\
\hline 5 & 5 & 0 & 0 & 0 & 0 & 0 & $\begin{array}{l}\text { PC tidak menyala } \\
\text { karena kartu melebihi } \\
\text { jarak verifikasi. }\end{array}$ \\
\hline
\end{tabular}

Tabel 4 berisi data hasil pengujian sensor RFID MFRC522 diberi jarak $3 \mathrm{~cm}$ antara kartu RFID ke RFID reader. Terdapat 3 parameter jenis pengujian yaitu kartu RFID, relay dan PC (Personal Computer). Data hasil pengujian sensor RFID MFRC522 pada tabel 4 menjelaskan bahwa RFID reader yang diberi jarak $3 \mathrm{~cm}$ antara kartu RFID ke RFID reader tidak dapat melakukan verifikasi karena melebihi jarak verifikasi antara kartu RFID ke RFID reader, maka sistem tidak akan memberi logika "HIGH" ataupun "LOW" pada relay yang terhubung dengan PC sehingga PC tidak dapat menyala dan tidak dapat mengirimkan notifikasi pada smartphone android melalui aplikasi blynk.

Tabel 5. Tabel Pengujian Sensor MFRC522 dengan jarak $4 \mathrm{~cm}$ antara kartu RFID ke RFID reader 
Procedia of Engineering and Life Science Vol. 1. No. 2 Juni 2021

Seminar Nasional \& Call Paper Fakultas Sains dan Teknologi (SENASAINS 2nd)

Universitas Muhammadiyah Sidoarjo

Tabel Pengujian Sensor MFRC522 dengan jarak 4 cm antara kartu RFID ke RFID reader.

\begin{tabular}{|c|c|c|c|c|c|c|c|}
\hline No & Percobaan & $\begin{array}{l}\text { Kartu } \\
\text { RFID }\end{array}$ & Relay & $\begin{array}{c}\text { PC } \\
\text { (Personal } \\
\text { Computer) } \\
\end{array}$ & $\begin{array}{l}\text { Rata- } \\
\text { rata }\end{array}$ & $\begin{array}{l}\text { Standar } \\
\text { Deviasi }\end{array}$ & Keterangan Alat \\
\hline 1 & 1 & 0 & 0 & 0 & 0 & 0 & $\begin{array}{c}\text { PC tidak menyala } \\
\text { karena kartu melebihi } \\
\text { jarak verifikasi. }\end{array}$ \\
\hline 2 & 2 & 0 & 0 & 0 & 0 & 0 & $\begin{array}{c}\text { PC tidak menyala } \\
\text { karena kartu melebihi } \\
\text { jarak verifikasi. }\end{array}$ \\
\hline 3 & 3 & 0 & 0 & 0 & 0 & 0 & $\begin{array}{l}\text { PC tidak menyala } \\
\text { karena kartu melebihi } \\
\text { jarak verifikasi. }\end{array}$ \\
\hline 4 & 4 & 0 & 0 & 0 & 0 & 0 & $\begin{array}{l}\text { PC tidak menyala } \\
\text { karena kartu melebihi } \\
\text { jarak verifikasi. }\end{array}$ \\
\hline 5 & 5 & 0 & 0 & 0 & 0 & 0 & $\begin{array}{l}\text { PC tidak menyala } \\
\text { karena kartu melebihi } \\
\text { jarak verifikasi. }\end{array}$ \\
\hline
\end{tabular}

Tabel 5 berisi data hasil pengujian sensor RFID MFRC522 diberi jarak $4 \mathrm{~cm}$ antara kartu RFID ke RFID reader. Terdapat 3 parameter jenis pengujian yaitu kartu RFID, relay dan PC (Personal Computer). Data hasil pengujian sensor RFID MFRC522 pada tabel 5 menjelaskan bahwa RFID reader yang diberi jarak $4 \mathrm{~cm}$ antara kartu RFID ke RFID reader tidak dapat melakukan verifikasi karena melebihi jarak verifikasi antara kartu RFID ke RFID reader, maka sistem tidak akan memberi logika "HIGH" ataupun "LOW" pada relay yang terhubung dengan PC sehingga PC tidak dapat menyala dan tidak dapat mengirimkan notifikasi pada smartphone android melalui aplikasi blynk.

Tabel 6. Tabel Pengujian Sensor MFRC522 dengan jarak $5 \mathrm{~cm}$ antara kartu RFID ke RFID reader

Tabel Pengujian Sensor MFRC522 tanpa penghalang dan jarak 5 cm antara kartu RFID ke RFID reader.

\begin{tabular}{|c|c|c|c|c|c|c|c|}
\hline No & Percobaan & $\begin{array}{l}\text { Kartu } \\
\text { RFID }\end{array}$ & Relay & $\begin{array}{c}\text { PC } \\
\text { (Personal } \\
\text { Computer) } \\
\end{array}$ & $\begin{array}{l}\text { Rata- } \\
\text { rata }\end{array}$ & $\begin{array}{l}\text { Standar } \\
\text { Deviasi }\end{array}$ & Keterangan Alat \\
\hline 1 & 1 & 0 & 0 & 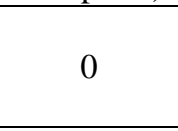 & 0 & 0 & $\begin{array}{l}\text { PC tidak menyala } \\
\text { karena kartu melebihi } \\
\text { jarak verifikasi. }\end{array}$ \\
\hline 2 & 2 & 0 & 0 & 0 & 0 & 0 & $\begin{array}{l}\text { PC tidak menyala } \\
\text { karena kartu melebihi } \\
\text { jarak verifikasi. }\end{array}$ \\
\hline 3 & 3 & 0 & 0 & 0 & 0 & 0 & $\begin{array}{l}\text { PC tidak menyala } \\
\text { karena kartu melebihi } \\
\text { jarak verifikasi. }\end{array}$ \\
\hline 4 & 4 & 0 & 0 & 0 & 0 & 0 & $\begin{array}{l}\text { PC tidak menyala } \\
\text { karena kartu melebihi } \\
\text { jarak verifikasi. }\end{array}$ \\
\hline 5 & 5 & 0 & 0 & 0 & 0 & 0 & $\begin{array}{l}\text { PC tidak menyala } \\
\text { karena kartu melebihi } \\
\text { jarak verifikasi. }\end{array}$ \\
\hline
\end{tabular}

Tabel 6 berisi data hasil pengujian sensor RFID MFRC522 diberi jarak $5 \mathrm{~cm}$ antara kartu RFID ke RFID reader. Terdapat 3 parameter jenis pengujian yaitu kartu RFID, relay dan PC (Personal Computer). Data hasil pengujian sensor RFID MFRC522 pada tabel 6 menjelaskan bahwa RFID reader yang diberi jarak $5 \mathrm{~cm}$ antara kartu RFID ke RFID reader tidak dapat melakukan verifikasi karena melebihi jarak verifikasi antara kartu RFID ke RFID reader, maka sistem tidak akan memberi logika "HIGH" ataupun "LOW" pada relay yang terhubung dengan PC sehingga PC tidak dapat menyala dan tidak dapat mengirimkan notifikasi pada smartphone android melalui aplikasi blynk. 


\section{KESIMPULAN}

Ketika ingin menghidupmatikan PC maka harus terlebih melakukan proses verifikasi dengan cara mendekatkan kartu RFID yang telah terdaftar pada sistem ke RFID reader, apabila kartu RFID yang terbaca oleh RFID reader sesuai terhadap sistem maka sistem akan mengirimkan logika "HIGH" ke relay yang tersambung pada PC sehingga PC dapat hidup atau mati, serta akan mengirimkan notifikasi ke smartphone berupa teks "PROSES VERIFIKASI BERHASIL, PC TELAH MENYALA." dan mendapatkan email yang berisi informasi berupa teks "PC KONDISI ON" apabila PC telah menyala, namun apabila PC telah mati maka sistem akan mengirimkan notifikasi ke smartphone berupa teks "PROSES VERIFIKASI BERHASIL, PC TELAH MATI." dan mendapatkan email yang berisi informasi berupa teks "PC KONDISI OFF". Sedangkan apabila kartu RFID yang terbaca oleh RFID reader tidak sesuai terhadap sistem maka sistem akan mengirimkan notifikasi ke smartphone berupa teks "PROSES VERIFIKASI GAGAL, KARTU TIDAK SESUAI." dan mendapatkan email yang berisi informasi berupa teks "AKSES DITOLAK" serta PC tidak dapat menyala atau mati karena kartu RFID tidak sesuai terhadap sistem. Namun kartu RFID tidak akan terbaca oleh RFID reader jika melebihi jarak verifikasi, oleh karena itu sistem tidak dapat memverifikasi kartu RFID yang didekatkan ke RFID reader yang menyebabkan PC tidak menyala jika kartu RFID melebihi jarak verifikasi.

Jarak maksimal untuk menentukan keberhasilan verifikasi kartu RFID ketika ingin menggunakan PC adalah dengan cara mendekatkan kartu RFID pada rentang jarak verifikasi $0 \mathrm{~cm}$ hingga 2,5 $\mathrm{cm}$ ke RFID reader, maka RFID reader dapat memverifikasi kartu RFID sehingga sistem dapat memberi perintah pada relay yang terhubung dengan PC agar PC dapat hidup atau mati dan mengirimkan notifikasi ke smartphone.

\section{REFERENSI}

[1] J. Jamaaluddin, "Utilization of Solar Power Plant as an Alternative Energy Sources Solar Applications in Building System," J. Sci. Appl. Eng., vol. 1, no. 2, pp. 83-87, 2018, doi: 10.31328/jsae.v1i2.890.

[2] Jamaaluddin, I. Robandi, and I. Anshory, "A very short-term load forecasting in time of peak loads using interval type-2 fuzzy inference system: A case study on java bali electrical system,” J. Eng. Sci. Technol., vol. 14, no. 1, pp. 464-478, 2019.

[3] J. Jamaaluddin, "Sistem Kontrol Pendingin Mobil Ramah Lingkungan Berbasis Android," Cyclotron, vol. 2, no. 1, 2019, doi: 10.30651/cl.v2i1.2528.

[4] R. Ahmad, "Perancangan Sistem Absensi Mahasiswa Terintegrasi dengan Sistem Akademik Menggunakan Teknologi RFID Ahmad," no. November, pp. 1-13, 2018.

[5] R. L. Singgeta and P. Manembu, "Sistem Pengamanan Pintu Rumah Dengan Rfid Berbasis Wireless Esp8266," vol. 2018, no. Ritektra, pp. 2-3, 2018, doi: 10.31219/osf.io/9q4z7.

[6] S. D. UTOMO, "Price Display Using Wemos," 2018.

[7] R. F. Putra, K. M. Lhaksmana, and D. Adytia, "Aplikasi IoT untuk Rumah Pintar dengan Fitur Prediksi Cuaca," e-Proceeding Eng., vol. 5, no. 1, pp. 1746-1760, 2018, [Online]. Available: https://openlibrary.telkomuniversity.ac.id/pustaka/files/141262/jurnal_eproc/aplikasi-iot-untuk-rumahpintar-dengan-fitur-prediksi-cuaca.pdf.

[8] M. Natsir, D. B. Rendra, and A. D. Y. Anggara, "Implementasi IOT Untuk Sistem Kendali AC Otomatis Pada Ruang Kelas di Universitas Serang Raya," J. PROSISKO Vol. 6 No. 1, vol. 6, no. 1, 2019.

[9] I. Anshory, D. Hadidjaja, and I. Sulistiyowati, "Monitoring Perubahan Tegangan dan Pemodelan Matematika Fungsi Transfer Motor BLDC Dengan System Identification Toolbox Program Studi Teknik Elektro, Fakultas Saintek, Universitas Muhammadiyah Sidoarjo," pp. 18-25.

[10] I. Anshory, I. Robandi, J. Jamaaluddin, A. Fudholi, and Wirawan, "Transfer function modeling and optimization speed response of BLDC motor e-bike using intelligent controller," J. Eng. Sci. Technol., vol. 16, no. 1, pp. 305-324, 2021.

[11] A. Ahfas, M. B. Ulum, D. H. R. Saputra, and S. Syahrorini, "Automatic Spray Desinfectant Chicken with Android Based on Arduino Uno," IOP Conf. Ser. Earth Environ. Sci., vol. 519, no. 1, 2020, doi: 10.1088/1755-1315/519/1/012013.

[12] A. Ahfas, D. Hadidjaja, S. Syahrorini, and J. Jamaaluddin, "Implementation of ultrasonic sensor as a chemical percol fluid level control based on Atmega 16," IOP Conf. Ser. Mater. Sci. Eng., vol. 1098, no. 4, p. 042046, 2021, doi: 10.1088/1757-899x/1098/4/042046.

[13] I. Anshory, D. Hadidjaja, and R. B. Jakaria, "BLDC Motor : Modeling and Optimization Speed Control Using Firefly Algorithm,” Dinamik, vol. 25, no. 2, pp. 51-58, 2020, doi: 10.35315/dinamik.v1i25.7851. 